\title{
Phytochemical Synthesis and Preliminary Characterization of Silver Nanoparticles Using Hesperidin
}

\author{
Anish Stephen and Sankar Seethalakshmi \\ Department of Pharmacology, Sri Ramachandra Medical College \& Research Institute, Chennai, India \\ Correspondence should be addressed to Anish Stephen; dranishstephen@gmail.com
}

Received 28 August 2013; Accepted 12 November 2013

Academic Editor: Kalimuthu Kalishwaralal

Copyright (C) 2013 A. Stephen and S. Seethalakshmi. This is an open access article distributed under the Creative Commons Attribution License, which permits unrestricted use, distribution, and reproduction in any medium, provided the original work is properly cited.

\begin{abstract}
This paper is the first of its kind for development of rapid and ecofriendly method for synthesis of silver nanoparticles from aqueous solution of silver nitrate using the flavonoid "hesperidin" and optimization of the methodology. There is formation of stable spherical silver nanoparticles in the size range of 20-40 nm. Optimization of methodology in terms of concentration of reactants and $\mathrm{pH}$ of the reaction mixture reduced the reaction time for silver nanoparticle formation to 2 mins. Silver nanoparticles (AgNPs) were characterized by UV-Vis spectroscopy and transmission electron microscopy (TEM). UV-vis spectroscopy derived spectrum demonstrated a peak of $430 \mathrm{~nm}$ which corresponds to the plasmon absorbance of silver nanoparticles. Transmission electron microscopy revealed spherical shaped silver nanoparticles in the size range of $20-40 \mathrm{~nm}$.
\end{abstract}

\section{Introduction}

Nanoparticles have become a subject of intense interest among the research community. These interests have been aroused by the lacunae in knowledge associated with silver nanoparticles and also the gaining momentum with which researches are uncovering the obscurities in knowledge surrounding the nanosciences. There is a rapid growth in the field of nanotechnology over the past few years and it has successfully ventured into the field of clinical medicine. Silver nanoparticles (Ag NPs) have occupied a central position in terms of research among all other metal nanoparticles [1]. There are several methods of synthesis of silver nanoparticles most of which fall under categories like physical methods, chemical methods, and the ecofriendly biomimetic methods [2]. Biomimetic methods of synthesis are the result of a growing need to develop cheap and ecofriendly methods for synthesis [3].

Physical approach for synthesis has several methods like evaporation/condensation and laser ablation, while in the chemical approach, the metal ions in solution are reduced in conditions favoring the subsequent formation of small metal clusters or aggregates [4]. From the utility perspective, along with nanodimensions the particles should be dispersed without agglomeration as well [2]. The properties exhibited by the metallic nanoparticles are size- and shape-dependent [5-7]. Biomimetic synthesis of silver nanoparticles is cost effective and environmental friendly and is also safe for applications in therapeutics [8]. Biological methods have emerged as an alternative to the conventional methods for synthesis of silver nanoparticles. Nanoparticle synthesis by biological methods results in a safer and biocompatible end product which is also cost effective and suitable for large scale supply since the production process can be scaled up $[9,10]$. Apart from plants, microbial sources like bacteria and fungus are also used in the silver nanoparticle synthesis [11]. For the preparation of silver nanoparticles (AgNPs) as colloid dispersion in water or organic solvents, chemical reduction is the most frequently applied method. Colloidal silver with particle diameters of several nanometers is the general yield of reduction of silver ions (Ag+) in aqueous solution [12]. Many research papers have reported the use of plant extracts for synthesis of silver nanoparticles, with a few of them being Sorghum bicolor, Helianthus annuus, Oryza sativa, Basella alba, Saccharum officinarum, and Zea mays [11]; pine, platanus leaves, ginkgo, magnolia, and persimmon [13]; Jatropha curcas seeds [14]; Acalypha indica leaf [15]; banana peel [16]; mulberry leaves [17]; Arbutus unedo leaf [18]; 
Chenopodium album leaf [19]; Rosa rugosa [20]; Trianthema decandra roots [21]; Ocimum sanctum (Tulsi) leaf [22]; Murraya koenigii (curry) leaf [23]; mangostana (mangosteen) leaf [24]; Ocimum sanctum stems and roots [25]. Many studies have highlighted the fact that phytochemical constituents present in the plant extracts play a major role in the reduction of silver ions into metallic silver and subsequent capping to prevent agglomeration. Phytochemicals are found in edible fruits and vegetables and help in the prevention of chronic and degenerative diseases by human metabolism modulation [26]. An one of the important groups of phytochemicals, flavonoids have proven pharmacological properties like anti-inflammatory, antiallergic, antibacterial, and antiviral properties [27-29] and have also been found to have cytotoxic antitumor properties and to be effective in neurodegenerative diseases [30, 31]. Flavonoids are free radical scavengers acting as antioxidants against free radicals [32]. Flavonoids are COX inhibitors [32]. Flavonoids prevent synthesis of PGs that suppress T-cells [33]; there are a huge number of research studies done in which silver nanoparticles are synthesized using plant extracts rich in flavonoids. Literature search reveals lacunae in synthesis of silver nanoparticles using flavonoids directly rather than using flavonoid rich plant extract.

This study attempts to synthesize silver nanoparticles using flavonoid directly rather than flavonoid rich plant extracts. Hesperidin was selected from the flavonoid inventory because of its easy availability and since it has been an integral phytochemical present in most of the fruits that we consume.

\section{Materials and Methods}

Hesperidin (HPLC 90\%) was purchased from Xian Xiaocao Botanical Development Co., Ltd., China. Silver nitrate (99.9999\% trace metals basis) was purchased from Sigma Aldrich. 99.8\% methanol was used. Milli-Q system was used for deionized water.

\section{Synthesis of Silver Nanoparticles and Optimization of Methodology}

Silver nanoparticles were prepared by chemical reduction of salt solution of silver nitrate using the flavonoid hesperidin. Aqueous silver nitrate solution was prepared with the strength of $1 \mathrm{mM}$ and $3 \mathrm{mM}$. Hesperidin solution was prepared by using methanol (99.8\%) as a solvent. In two glass flasks, $10 \mathrm{mg}$ and $30 \mathrm{mg}$ of hesperidin were taken, respectively. Into the two flasks $100 \mathrm{~mL}$ of methanol was added and the mixture was subjected to sonication for 5 mins in order to ensure that there is no particle matter left in the solution. The resultant strengths of the two hesperidin solutions were $100 \mu \mathrm{gm} / \mathrm{mL}$ and $300 \mu \mathrm{gm} / \mathrm{ml}$. The $\mathrm{pH}$ of the hesperidin solution which is acidic is raised to a basic level of around 12 by adding few drops of freshly prepared $\mathrm{NaOH}$.

$90 \mathrm{ml}$ of aqueous solution of silver nitrate was taken in a flask and kept on a magnetic stirrer into which $10 \mathrm{ml}$ of hesperidin solution was added drop by drop using a
TABLE 1: Combinations in the flasks.

$10 \mathrm{~mL}$ hesperidin $(100 \mu \mathrm{gm} / \mathrm{mL})$ in $90 \mathrm{~mL}$ silver nitrate solution $(1 \mathrm{mM})(1: 10$ ratio $)$

$10 \mathrm{~mL}$ hesperidin $(300 \mu \mathrm{gm} / \mathrm{mL})$ in $90 \mathrm{~mL}$ silver nitrate solution $(1 \mathrm{mM})(1: 10$ ratio $)$

$10 \mathrm{~mL}$ hesperidin $(100 \mu \mathrm{gm} / \mathrm{mL})$ in $90 \mathrm{~mL}$ silver nitrate solution (3 mM) (1:10 ratio)

$10 \mathrm{~mL}$ hesperidin $(300 \mu \mathrm{gm} / \mathrm{mL})$ in $90 \mathrm{ml}$ silver nitrate solution (3 mM) (1:10 ratio)

$10 \mathrm{~mL}$ methanol in $1 \mathrm{mM}$ silver nitrate solution $(90 \mathrm{~mL})$

(1:10 ratio): control

micropipette. In total there were 5 flasks in the combinations as mentioned in Table 1.

\section{Characterization Studies}

Color of the reaction mixture was observed. UV-vis absorption spectra were measured using Synergy H4 Hybrid Multimode Microplate Reader (BioTek). Through UV-vis absorption spectra, formation process of silver nanoparticles, confirmation of formation of silver nanoparticles, and the stability of the synthesized silver nanoparticles were studied. Sample preparation was done by diluting a small aliquot of the reaction mixture solution in Milli-Q water. The sample was taken as soon as half of the hesperidin solution was added, which corresponds to the start of change in color of the reaction mixture, after the entire $10 \mathrm{ml}$ of hesperidin solution was added and soon after the color of the reaction mixture changed completely to brownish yellow, that is, around 2 mins after the last drop of hesperidin solution was added and also at regular time intervals after that.

Transmission electron microscopy (TEM) analysis of synthesized silver nanoparticles was done using Tecnai G2 spirit Biotwin TEM system (FEI electron microscope). Sample preparation for TEM analysis was done by putting a small drop of the colloid solution on the TEM grid (formvar with carbon coating) and allowing it to dry at room temperature for two hours.

\section{Results and Discussions}

Physical observation revealed the change in color of the solution from colorless to brownish yellow within minutes of adding the hesperidin solution to the aquous silver nitrate solution (Figure 1). Similar change in color was seen in all the four combinations except control (Figure 2).

The color started to change when around $5 \mathrm{ml}$ of hesperidin out of the $10 \mathrm{ml}$ was added and completely changed to brownish yellow within 2 mins of adding the last drop.

The change in color was more or less the same in all the samples except the control sample. Formation of silver nanoparticles by reduction of the aquous sol of silver nitrate on exposure to hesperidin solution was observed from the change in color of the reaction mixture. Silver nanoparticles exhibit a yellowish brown color in aquous solution due to excitation of surface plasmon vibrations [34]. The change in 


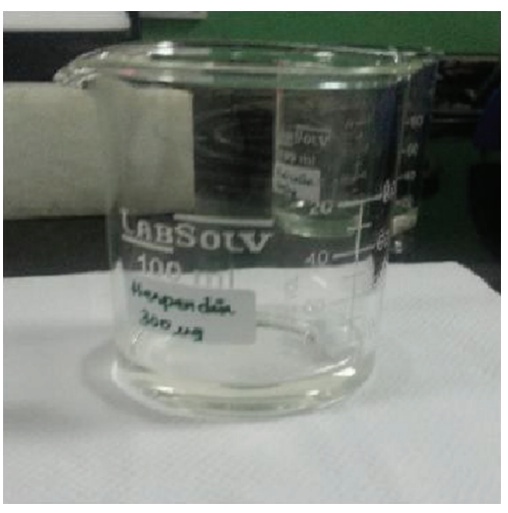

Hesperidin solution

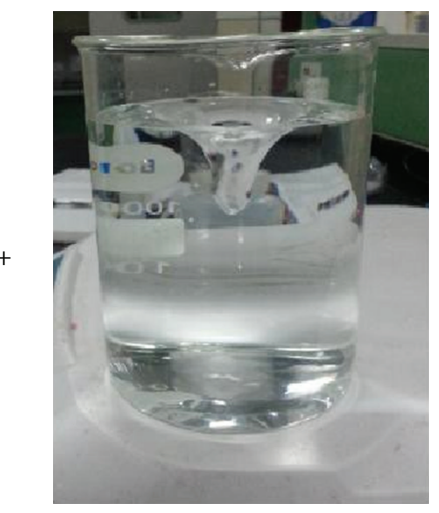

Silver nitrate solution on magnetic stirrer

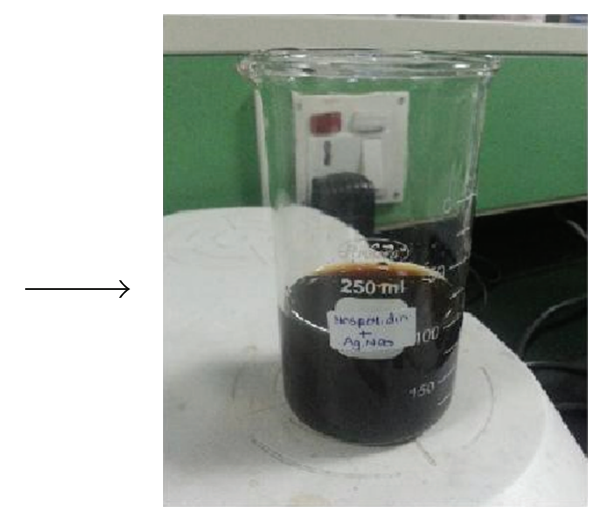

Silver nitrate solution $(90 \mathrm{~mL})+$ hesperidin solution $(10 \mathrm{~mL})$

FIGURE 1: Formation of silver nanoparticles.

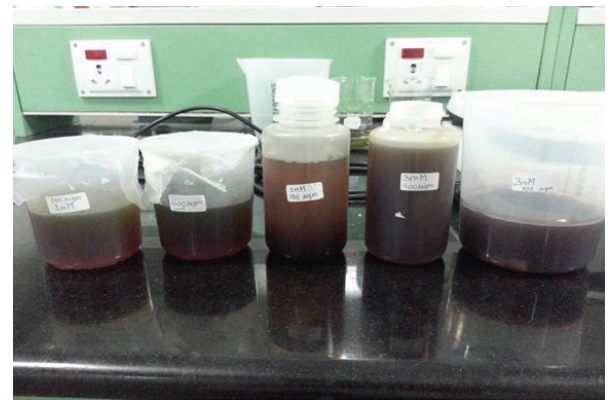

FIGURE 2: Different combinations.

color indicated the formation of silver nanoparticles. This suggests that there is a formation of elemental silver having nanodimensions from the silver ions in the silver nitrate solution. The basis of synthesis can be explained in two steps. In the first step silver atoms $(\mathrm{Ag} 0)$ are formed initially due to the reduction of various complexes with $\mathrm{Ag}+$ ions followed by the second step in which there is a formation of oligomeric clusters due to agglomeration and these clusters eventually lead to the formation of colloidal Ag particles [12].

UV-Vis spectroscopy analysis was done in the wavelength range of $300 \mathrm{~nm}$ to $700 \mathrm{~nm}$. The absorption peak (wavelength at mean maximum optical density) was obtained to be 420 $\mathrm{nm}$ (for $100 \mu \mathrm{gm} / \mathrm{ml}$ hesperidin solution combinations) and $430 \mathrm{~nm}(300 \mu \mathrm{gm} / \mathrm{mL}$ hesperidin solution combinations) for the samples taken after the complete change of color except control. Typical absorption band for silver nanoparticles was observed in visible light region for silver nanoparticles [35]. The plasmon peak and the full-width of half-maximum (FWHM) depend on the extent of colloid aggregation [35].

The process of synthesis was complete in few mins of reaction time and the time dependent change in the absorption peak is presented (Figures 7, 8, and 9).

It can be seen how the absorption peak which corresponds to nanoparticle synthesis has evolved over a period of time and corresponds to the change in the color of the reaction mixture

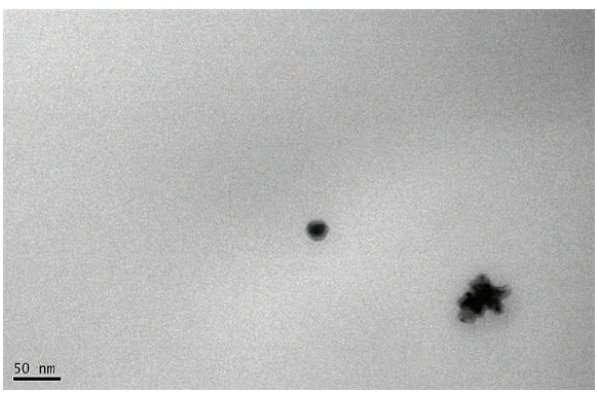

Figure 3: TEM image at 180,000 magnification.

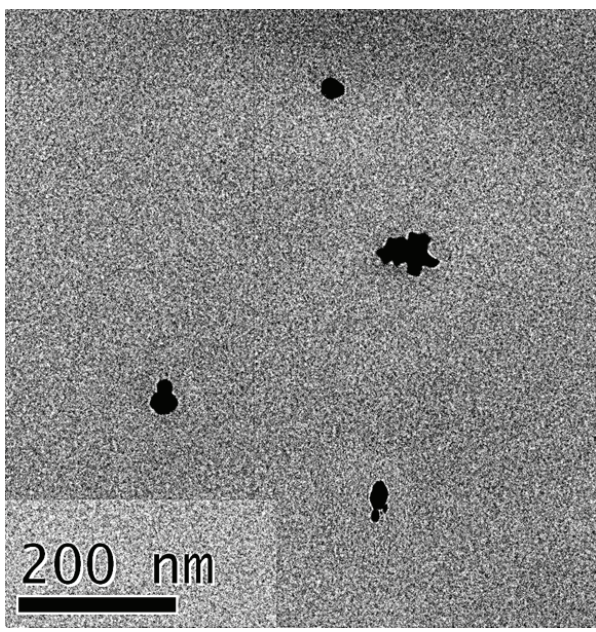

FIgUre 4: TEM image at 49,000 magnification.

To monitor stability of the colloid solution, absorption of the colloid was measured at the time of complete color change and various intervals thereafter. There was no obvious change in peak position (wavelength at mean maximum optical density) and maximum optical density when studied at various time intervals which suggests a highly stable colloid and aggregation after formation not to be of significance [36]; as the particles increase in size, the absorption peak 


\begin{tabular}{ccccc}
\hline Well & $\begin{array}{c}\text { Mean min OD } \\
\text { (spectrum) }\end{array}$ & $\begin{array}{c}\text { Wavelength } \\
\text { at mean } \\
\text { min OD } \\
\text { (spectrum) }\end{array}$ & $\begin{array}{c}\text { Mean max OD } \\
\text { (spectrum) }\end{array}$ & $\begin{array}{c}\text { Wavelength } \\
\text { at mean } \\
\text { max OD } \\
\text { (spectrum) }\end{array}$ \\
\hline $\begin{array}{c}\mathrm{mM} / 300 \\
(\mathrm{E} 7)\end{array}$ & 0.094 & 700 & 3.78 & 430 \\
\hline
\end{tabular}

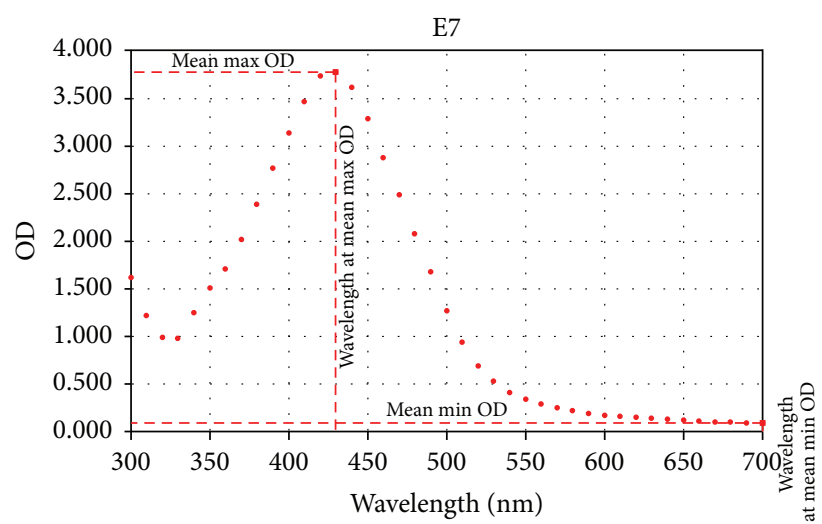

Figure 5: UV-Vis data of $300 \mu \mathrm{l} / \mathrm{ml}$ hesperidin $+1 \mathrm{mM}$ of silver nitrate solution.

\begin{tabular}{ccccc}
\hline Well & $\begin{array}{c}\text { Mean min OD } \\
\text { (spectrum) }\end{array}$ & $\begin{array}{c}\text { Wavelength } \\
\text { at mean } \\
\text { min OD } \\
\text { (spectrum) }\end{array}$ & $\begin{array}{c}\text { Mean max OD } \\
\text { (spectrum) }\end{array}$ & $\begin{array}{c}\text { Wavelength } \\
\text { at mean } \\
\text { max OD } \\
\text { (spectrum) }\end{array}$ \\
\hline $\begin{array}{c}3 \mathrm{mM} / 300 \\
\text { (E9) }\end{array}$ & 0.117 & 700 & 2.355 & 430 \\
\hline
\end{tabular}

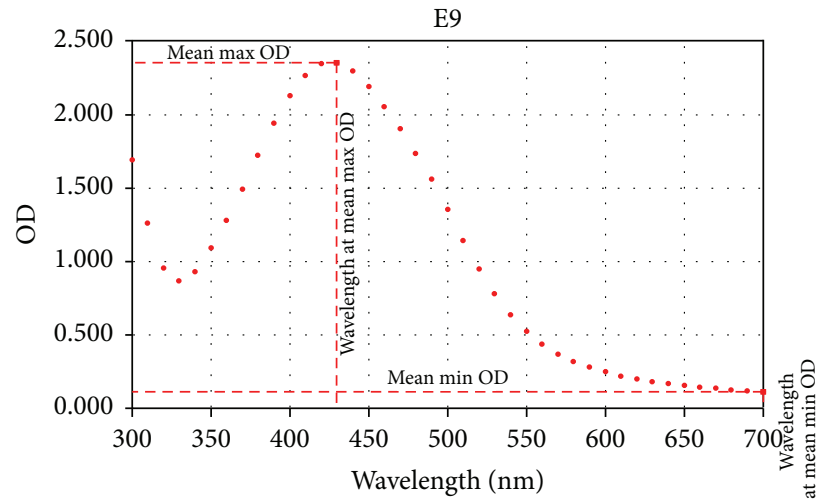

Figure 6: UV-Vis data of $300 \mu \mathrm{l} / \mathrm{ml}$ hesperidin $+3 \mathrm{mM}$ of silver nitrate solution.

usually shifts toward the red wavelengths [37] which further reinforces the fact that there was no change in the particle size over a period of time.

UV-Vis spectroscopy data for the following combinations " $1 \mathrm{~mm}$ silver nitrate $-300 \mu \mathrm{gm} / \mathrm{mL}$ hesperidin" and " $3 \mathrm{~mm}$ silver nitrate $-300 \mu \mathrm{gm} / \mathrm{mL}$ hesperidin" is presented (Figures 5 and 6 ).

It is observed that both samples have a peak (wavelength at mean maximum optical density) of $430 \mathrm{~nm}$. It is also observed that the mean maximum optical density is $3.78 \mathrm{~cm}^{-1}$ and $2.355 \mathrm{~cm}^{-1}$, respectively. These values can be used to quantify the concentration of silver nanoparticles in various combinations. Using the Beer-Lambert law (which states that

\begin{tabular}{ccccc}
\hline Well & $\begin{array}{c}\text { Mean min OD } \\
\text { (spectrum) }\end{array}$ & $\begin{array}{c}\text { Wavelength } \\
\text { at mean } \\
\text { min OD } \\
\text { (spectrum) }\end{array}$ & $\begin{array}{c}\text { Mean max OD } \\
\text { (spectrum) }\end{array}$ & $\begin{array}{c}\text { Wavelength } \\
\text { at mean } \\
\text { max OD } \\
\text { (spectrum) }\end{array}$ \\
\hline H0 & 0.113 & 700 & 1.938 & 300 \\
\hline
\end{tabular}

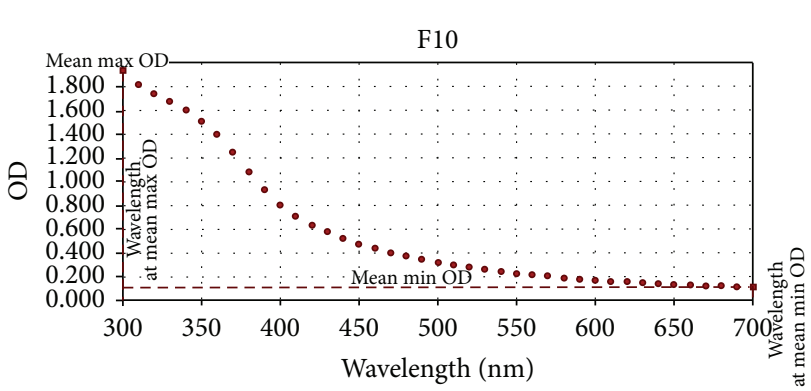

FIGURE 7: UV-Vis spectrometry data of reaction mixture at the start of change in color.

\begin{tabular}{ccccc}
\hline Well & $\begin{array}{c}\text { Mean min OD } \\
\text { (spectrum) }\end{array}$ & $\begin{array}{c}\text { Wavelength } \\
\text { at mean } \\
\text { min OD } \\
\text { (spectrum) }\end{array}$ & $\begin{array}{c}\text { Mean max OD } \\
\text { (spectrum) }\end{array}$ & $\begin{array}{c}\text { Wavelength } \\
\text { at mean } \\
\text { max OD } \\
\text { (spectrum) }\end{array}$ \\
\hline H1 & 0.212 & 700 & 1.638 & 300 \\
\hline
\end{tabular}

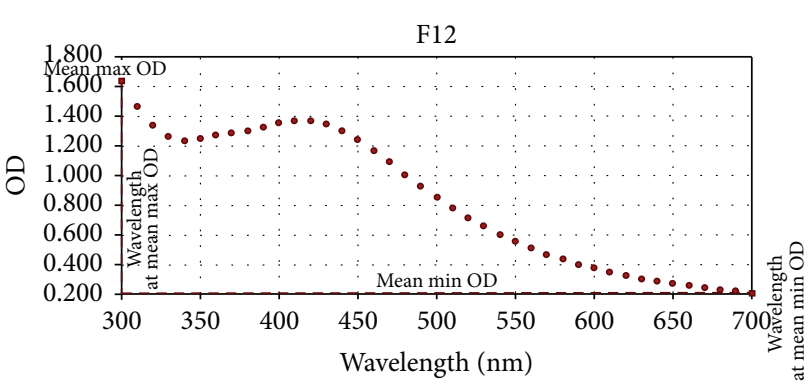

FIGURE 8: UV-Vis spectrometry data of reaction mixture taken after complete mixing of $10 \mathrm{ml}$ hesperidin of $100 \mu \mathrm{gm}$ per $\mathrm{ml}$.

the optical density (OD, a measure of the amount of light transmitted through a solution) has a linear relationship with concentration) the concentrations of silver nanoparticle solutions were compared which pointed out that the combination "1 $\mathrm{mm}$ silver nitrate $-300 \mu \mathrm{gm} / \mathrm{mL}$ hesperidin" has a better yield and was further studied using TEM.

Transmission electron microscopy helps analyzing the morphology and size of the particles. Observed images were of magnification of 180,000 (Figure 3) and 49,000 (Figure 4) and shows spherical silver nanoparticles in the size range of 20 to $40 \mathrm{~nm}$ with capping on it.Clumping of particles resulting in a larger particle is also seen.

\section{Conclusion}

We have developed a fast, ecofriendly, and convenient method for synthesis of silver nanoparticles from silver nitrate using hesperidin at room temperature. Color changes from colorless to yellowish brown due to surface plasmon resonance during the reaction with hesperidin solution 


\begin{tabular}{ccccc}
\hline Well & $\begin{array}{c}\text { Mean min OD } \\
\text { (spectrum) }\end{array}$ & $\begin{array}{c}\text { Wavelength } \\
\text { at mean } \\
\text { min OD } \\
\text { (spectrum) }\end{array}$ & $\begin{array}{c}\text { Mean max OD } \\
\text { (spectrum) }\end{array}$ & $\begin{array}{c}\text { Wavelength } \\
\text { at mean } \\
\text { max OD } \\
\text { (spectrum) }\end{array}$ \\
\hline $\mathrm{H} 2$ & 0.198 & 700 & 1.868 & 420 \\
\hline
\end{tabular}

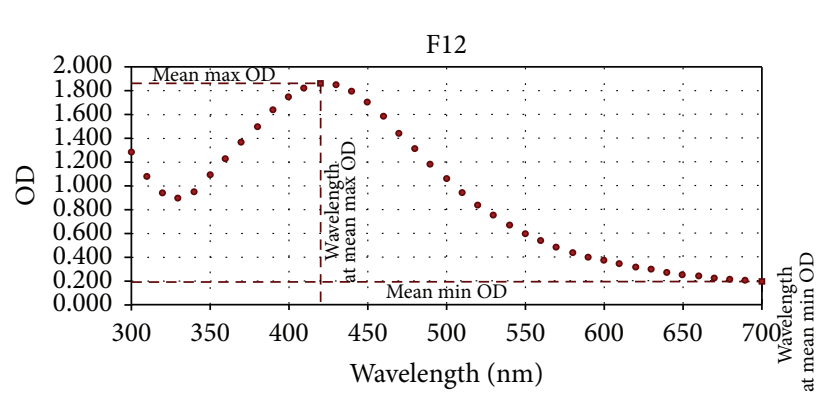

FIGURE 9: UV-Vis spectrometry data of reaction mixture after complete change in color (2 mins).

resulting in the formation of silver nanoparticles, which is confirmed by TEM and UV-vis spectroscopy. Hesperidin is found suitable for the synthesis of silver nanoparticles within two mins. Spherical, polydispersed AgNPs of particle sizes ranging from 20 to $40 \mathrm{~nm}$ with an average size of $30 \mathrm{~nm}$ are obtained. Further studies will be conducted to study the pharmacological properties of the synthesized silver nanoparticles from hesperidin.

\section{Acknowledgments}

This work was supported by Talent Search Scheme of Indian Council of Medical Research. Experiments were conducted at the Research Facility of Sri Ramachandra Medical College and Research Institute, Chennai. The TEM studies were done at National Centre for Biological Research, Bangalore.

\section{References}

[1] K. Y. Wong, "Silver nanoparticles in medicine: is the panacea here," Nanomedicine: Nanotechnology, Biology and Medicine, vol. 8, no. 6, pp. 935-940, 2012.

[2] K. M. M. Abou El-Nour, A. Eftaiha, A. Al-Warthan, and R. A. A. Ammar, "Synthesis and applications of silver nanoparticles," Arabian Journal of Chemistry, vol. 3, no. 3, pp. 135-140, 2010.

[3] K. Kalishwaralal, V. Deepak, S. Ramkumarpandian, H. Nellaiah, and G. Sangiliyandi, "Extracellular biosynthesis of silver nanoparticles by the culture supernatant of Bacillus licheniformis," Materials Letters, vol. 62, no. 29, pp. 4411-4413, 2008.

[4] G. B. Khomutov and S. P. Gubin, "Interfacial synthesis of noble metal nanoparticles," Materials Science and Engineering C, vol. 22, no. 2, pp. 141-146, 2002.

[5] Y. Choi, N.-H. Ho, and C.-H. Tung, "Sensing phosphatase activity by using gold nanoparticles," Angewandte ChemieInternational Edition, vol. 46, no. 5, pp. 707-709, 2007.

[6] K. Yoosaf, B. I. Ipe, C. H. Suresh, and K. G. Thomas, "In situ synthesis of metal nanoparticles and selective naked-eye detection of lead ions from aqueous media," The Journal of Physical Chemistry C, vol. 111, no. 34, pp. 12839-12847, 2007.
[7] J. Y. Song and B. S. Kim, "Rapid biological synthesis of silver nanoparticles using plant leaf extracts," Bioprocess and Biosystems Engineering, vol. 32, no. 1, pp. 79-84, 2009.

[8] B. Wiley, Y. Sun, B. Mayers, and Y. Xia, "Shape-controlled synthesis of metal nanostructures: the case of silver," Chemistry $-A$ European Journal, vol. 11, no. 2, pp. 454-463, 2005.

[9] N. Roy and A. Barik, "Green synthesis of silver nanoparticles from the unexploited weed resources," International Journal of Nanotechnology, vol. 4, p. 95, 2010.

[10] K. Govindaraju, S. Tamilselvan, V. Kiruthiga, and G. Singaravelu, "Biogenic silver nanoparticles by Solanum torvum and their promising antimicrobial activity," Journal of Biopesticides, vol. 3, no. 1, pp. 394-399, 2010.

[11] D. Mandal, M. E. Bolander, D. Mukhopadhyay, G. Sarkar, and P. Mukherjee, "The use of microorganisms for the formation of metal nanoparticles and their application," Applied Microbiology and Biotechnology, vol. 69, no. 5, pp. 485-492, 2006.

[12] S. Kapoor, D. Lawless, P. Kennepohl, D. Meisel, and N. Serpone, "Reduction and aggregation of silver ions in aqueous gelatin solutions," Langmuir, vol. 10, no. 9, pp. 3018-3022, 1994.

[13] J. Y. Song and B. S. Kim, "Rapid biological synthesis of silver nanoparticles using plant leaf extracts," Bioprocess and Biosystems Engineering, vol. 32, no. 1, pp. 79-84, 2009.

[14] H. Bar, D. K. Bhui, G. P. Sahoo, P. Sarkar, S. Pyne, and A. Misra, "Green synthesis of silver nanoparticles using seed extract of Jatropha curcas," Colloids and Surfaces A, vol. 348, no. 1-3, pp. 212-216, 2009.

[15] C. Krishnaraj, E. G. Jagan, S. Rajasekar, P. Selvakumar, P. T. Kalaichelvan, and N. Mohan, "Synthesis of silver nanoparticles using Acalypha indica leaf extracts and its antibacterial activity against water borne pathogens," Colloids and Surfaces B, vol. 76, no. 1, pp. 50-56, 2010.

[16] A. Bankar, B. Joshi, A. R. Kumar, and S. Zinjarde, "Banana peel extract mediated novel route for the synthesis of silver nanoparticles," Colloids and Surfaces A, vol. 368, no. 1-3, pp. 58-63, 2010.

[17] A. M. Awwad and N. M. Salem, "Green synthesis of silver nanoparticles by mulberry leaves extract," Journal of Nanoscience and Nanotechnology, vol. 2, no. 4, pp. 125-128, 2012.

[18] P. Kouvaris, A. Delimitis, V. Zaspalis, D. Papadopoulos, S. A. Tsipas, and N. Michailidis, "Green synthesis and characterization of silver nanoparticles produced using Arbutus Unedo leaf extract," Materials Letters, vol. 76, pp. 18-20, 2012.

[19] A. D. Dwivedi and K. Gopal, "Biosynthesis of silver and gold nanoparticles using Chenopodium album leaf extract," Colloids and Surfaces A, vol. 369, no. 1-3, pp. 27-33, 2010.

[20] A. M. Awwad, N. M. Salem, and A. Abdeen, "Biosynthesis of silver nanoparticles using Olea europaea leaves extract and its antibacterial activity," Journal of Nanoscience and Nanotechnology, vol. 2, no. 4, pp. 164-170, 2012.

[21] E. Geethalakshmi and D. V. Sarada, "Synthesis of plant-mediated silver nanoparticles using Trianthema decandra extract and evaluation of their anti microbial activities," International Journal of Engineering Science and Technology, vol. 2, no. 5, pp. 970-975, 2010.

[22] G. Singhal, R. Bhavesh, K. Kasariya, A. R. Sharma, and R. P. Singh, "Biosynthesis of silver nanoparticles using Ocimum sanctum (Tulsi) leaf extract and screening its antimicrobial activity," Journal of Nanoparticle Research, vol. 13, no. 7, pp. 29812988, 2011. 
[23] L. Christensen, S. Vivekanandhan, M. Misra, and A. K. Mohanty, "Biosynthesis of silver nanoparticles using murraya koenigii (curry leaf): an investigation on the effect of broth concentration in reduction mechanism and particle size," Advanced Materials Letters, vol. 2, pp. 429-434, 2011.

[24] R. Veerasamy, T. Z. Xin, S. Gunasagaran et al., "Biosynthesis of silver nanoparticles using mangosteen leaf extract and evaluation of their antimicrobial activities," Journal of Saudi Chemical Society, vol. 15, no. 2, pp. 113-120, 2011.

[25] N. Ahmad, S. Sharma, M. K. Alam et al., "Rapid synthesis of silver nanoparticles using dried medicinal plant of basil," Colloids and Surfaces B, vol. 81, no. 1, pp. 81-86, 2010.

[26] E. Tripoli, M. L. Guardia, S. Giammanco, D. D. Majo, and M. Giammanco, "Citrus flavonoids: molecular structure, biological activity and nutritional properties: a review," Food Chemistry, vol. 104, no. 2, pp. 466-479, 2007.

[27] T. P. T. Cushnie and A. J. Lamb, "Antimicrobial activity of flavonoids," International Journal of Antimicrobial Agents, vol. 26, no. 5, pp. 343-356, 2005.

[28] M. T. Murray, "Quercitin: nature's antihistamine," Better Nutrition, vol. 60, no. 4, p. 10, 1998.

[29] N. C. Cook and S. Samman, "Flavonoids-chemistry, metabolism, cardioprotective effects, and dietary sources," The Journal of Nutritional Biochemistry, vol. 7, no. 2, pp. 66-76, 1996.

[30] E. de Rijke, P. Out, W. M. A. Niessen, F. Ariese, C. Gooijer, and U. A. T. Brinkman, "Analytical separation and detection methods for flavonoids," Journal of Chromatography A, vol. 1112, no. 1-2, pp. 31-63, 2006.

[31] L. Chebil, C. Humeau, A. Falcimaigne, J.-M. Engasser, and M. Ghoul, "Enzymatic acylation of flavonoids," Process Biochemistry, vol. 41, no. 11, pp. 2237-2251, 2006.

[32] R. S. Pal, G. Ariharasivakumar, K. Girhepunje, and A. Upadhyay, "In-vitro antioxidative activity of phenolic and flavonoid compounds extracted from seeds of Abrus precatorius," International Journal of Pharmacy and Pharmaceutical Sciences, vol. 1, no. 2, pp. 136-140, 2009.

[33] L. Bitis, S. Kultur, G. Melkoglu, N. Ozsoy, and A. Can, "Flavonoids and antioxidant activity of Rosa agrestis leaves," Natural Product Research, vol. 24, no. 6, pp. 580-589, 2010.

[34] Y. S. Jae and S. K. Beom, "Rapid biological synthesis of silver nanoparticles using plant leaf extracts," Bioprocess and Biosystems Engineering, vol. 32, no. 1, pp. 79-84, 2009.

[35] S. Yamamoto, K. Fujiwara, and H. Watarai, "Surface-enhanced Raman scattering from oleate-stabilized silver colloids at a liquid/liquid interface," Analytical Sciences, vol. 20, no. 9, pp. 1347-1352, 2004.

[36] A. Sileikaite, I. Prosycevas, J. Puiso, A. Juraitis, and A. Guobienè, "Analysis of silver nanoparticles produced by chemical reduction of silver salt solution," Materials Science, vol. 12, no. 4, 2006.

[37] Y. Xia and N. J. Halas, "Shape-controlled synthesis and surface plasmonic properties of metallic nanostructures," MRS Bulletin, vol. 30, pp. 338-3343, 2005. 

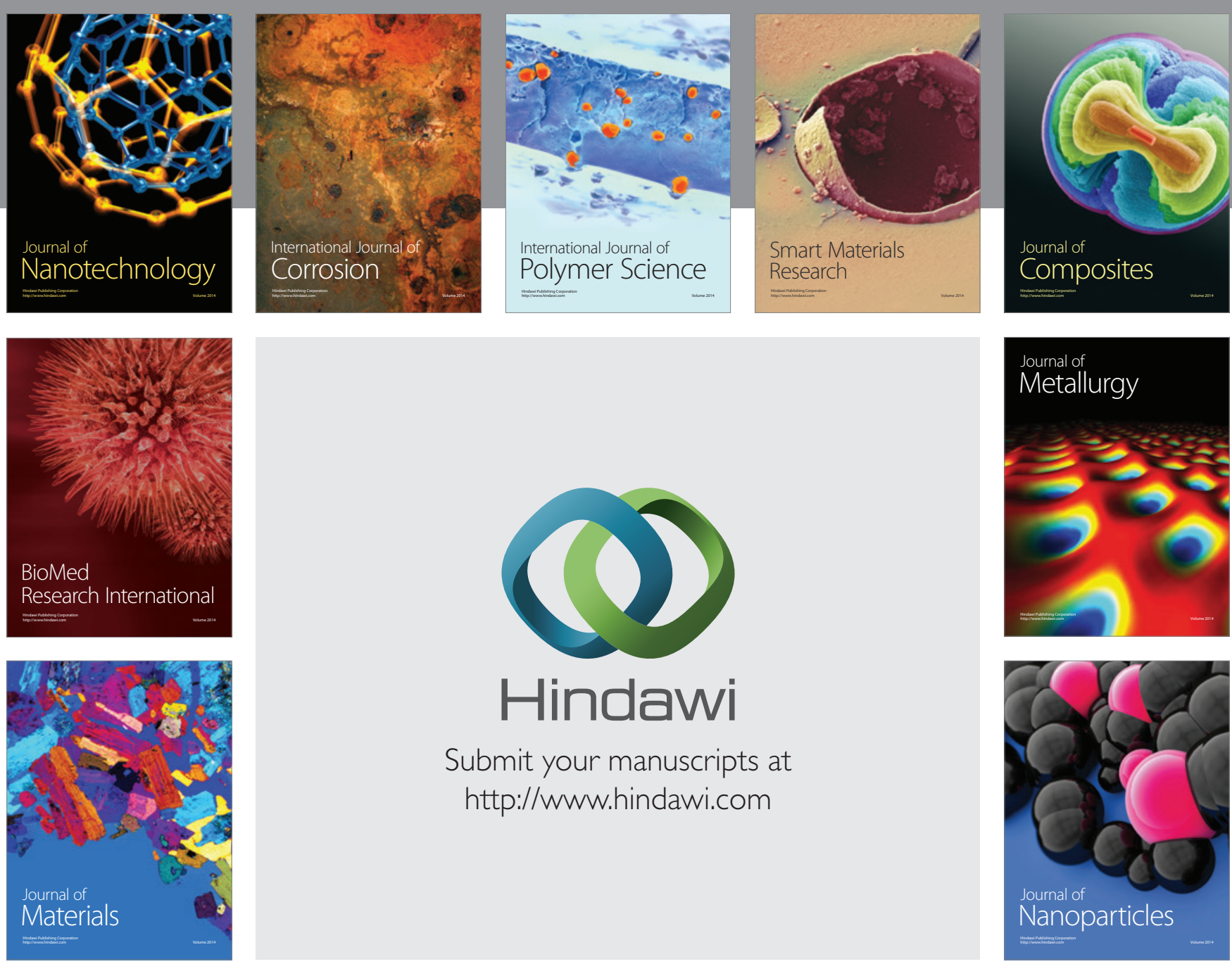

Submit your manuscripts at http://www.hindawi.com
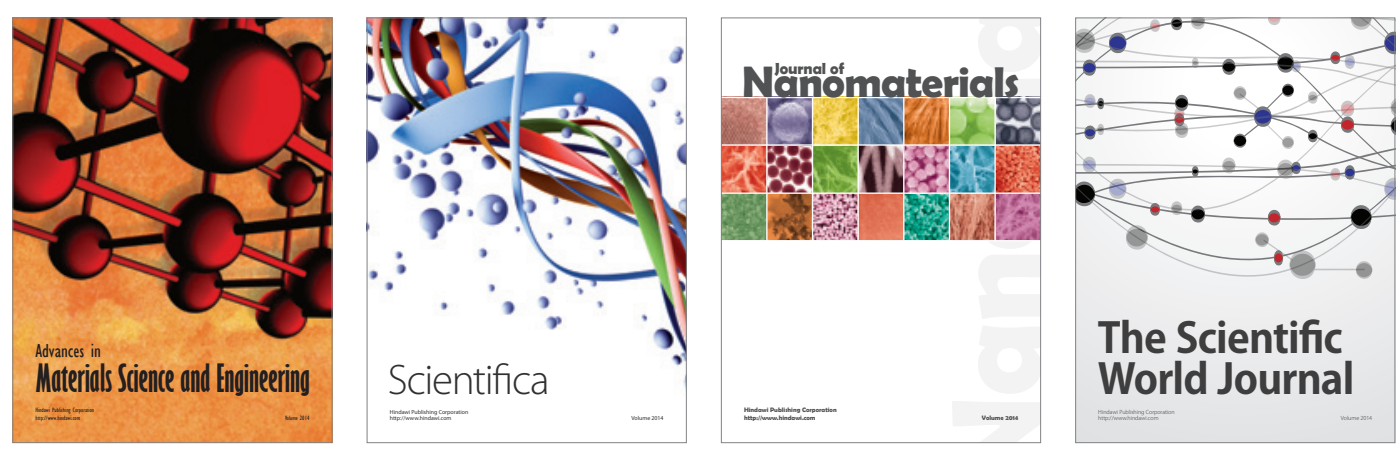

\section{The Scientific World Journal}
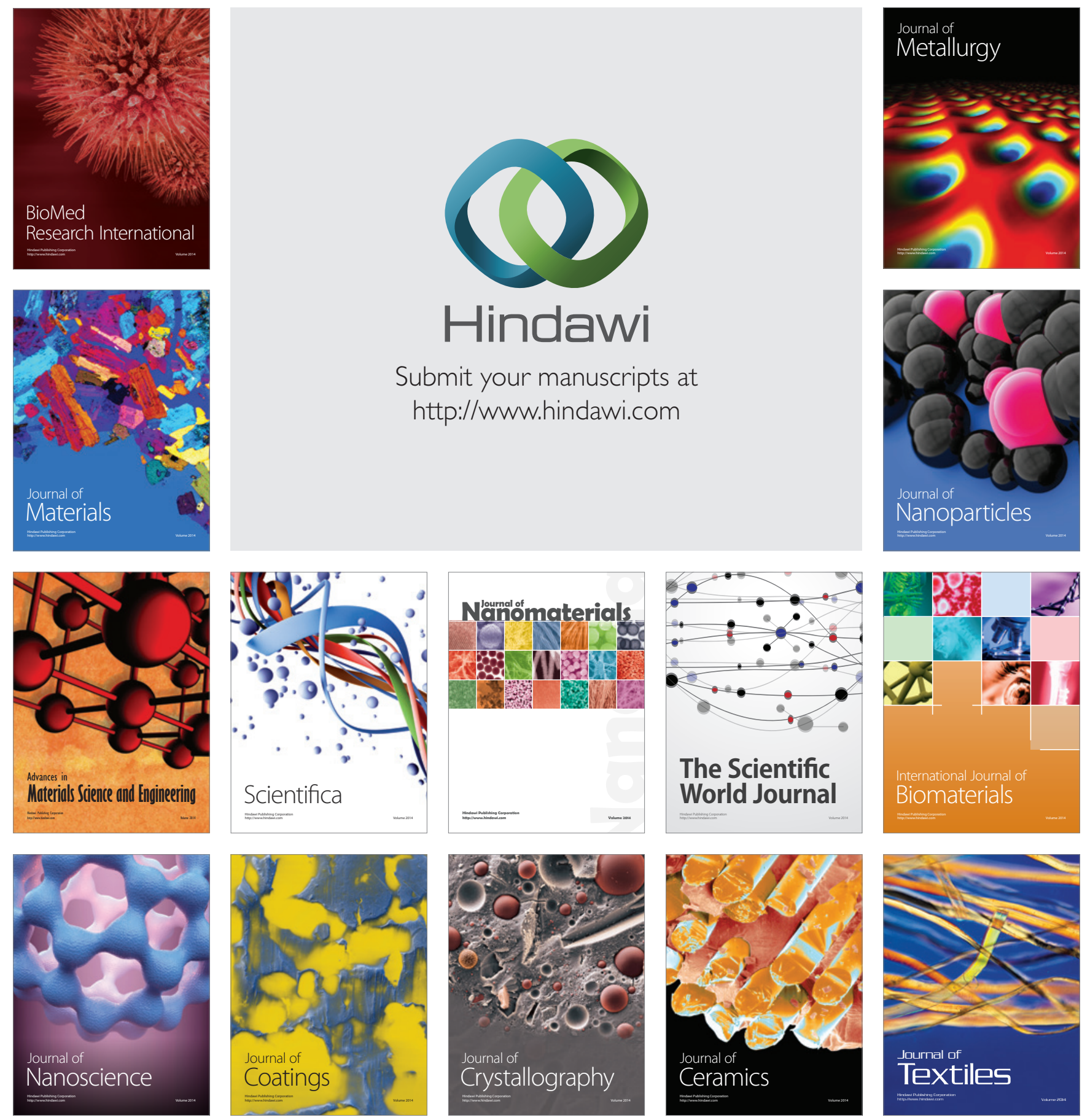